\title{
Rhino-orbital mucormycosis due to Apophysomyces ossiformis in a patient with diabetes mellitus: a case report
}

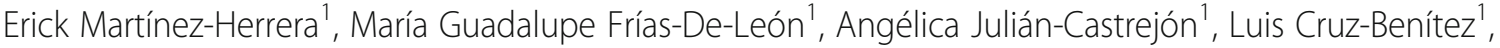 \\ Juan Xicohtencatl-Cortes ${ }^{2}$ and Rigoberto Hernández-Castro ${ }^{3 *}$ (i)
}

\begin{abstract}
Background: The most common aetiological agents of mucormycosis are Rhizopus, Mucor, Apophysomyces and Lichtheimia. Apophysomyces is comparatively rare, as it has been reported in less than $3 \%$ of mucormycosis cases. The genus Apophysomyces includes six species, and only A. elegans, A. mexicanus, A. variabilis and A. ossiformis have been reported to cause infections in both immunocompetent and immunocompromised patients.

Case presentation: We present a case of a 46-year-old male patient with bilateral blepharoedema, corneal opacity in the left eye and poorly controlled diabetes mellitus. The patient was subjected to total maxillectomy, exenteration of the left orbit and treatment with liposomal amphotericin B. Direct mycological analysis with $\mathrm{KOH}$ 10\% revealed hyaline, coenocytic, long and wide hyphae. Apophysomyces ossiformis was identified from maxillary biopsy using 18S-ITS1-5.8S-ITS2-28S rRNA gene amplification and sequencing. The patient requested to be transferred to another hospital to continue treatment, where he died on the ninth day after admittance.

Conclusion: To the best of our knowledge, this is the first case of rhino-orbital mucormycosis due to $A$. ossiformis with a fatal outcome. This case reveals the need to identify the fungus causing mucormycosis with molecular methods to identify adequate treatment therapies for patients with this infection.
\end{abstract}

Keywords: Apophysomyces ossiformis, Diabetes mellitus, Invasive fungal disease, Mucormycosis

\section{Background}

Mucormycosis is an invasive infection caused by Mucorales [1]. The main risk factors for this mycosis are diabetes mellitus type 2, immunosuppression, neutropenia, metabolic acidosis, leukaemia, lymphoma, and organ transplants [2]. The clinical presentation can be pulmonary, gastrointestinal, cutaneous, and disseminated; however, the most frequent presentation is rhinocerebral, with a high mortality rate $[1,3]$. The most common aetiological agents are Rhizopus, Mucor,

\footnotetext{
*Correspondence: rhc@unam.mx

${ }^{3}$ Departamento de Ecología de Agentes Patógenos, Hospital General "Dr.

Manuel Gea González", Sección XVI, Tlalpan 14080, Ciudad de México,

Mexico

Full list of author information is available at the end of the article
}

Apophysomyces and Lichtheimia. Apophysomyces is comparatively rare, as it has been reported in less than 3\% of mucormycosis cases [4]. The genus Apophysomyces includes six species (A. elegans, A. mexicanus, $A$. ossiformis, A. thailandensis, A. trapeziformis, and A. variabilis), and only A. elegans, A. mexicanus, A. ossiformis and $A$. variabilis have been reported to cause infections in both immunocompetent and immunocompromised patients [5-7]. We present the first case of rhino-orbital mucormycosis due to A. ossiformis in a patient with poorly controlled diabetes from the central region of Mexico.

(c) The Author(s). 2020 Open Access This article is licensed under a Creative Commons Attribution 4.0 International License, which permits use, sharing, adaptation, distribution and reproduction in any medium or format, as long as you give appropriate credit to the original author(s) and the source, provide a link to the Creative Commons licence, and indicate if changes were made. The images or other third party material in this article are included in the article's Creative Commons licence, unless indicated otherwise in a credit line to the material. If material is not included in the article's Creative Commons licence and your intended use is not permitted by statutory regulation or exceeds the permitted use, you will need to obtain permission directly from the copyright holder. To view a copy of this licence, visit http://creativecommons.org/licenses/by/4.0/ The Creative Commons Public Domain Dedication waiver (http://creativecommons.org/publicdomain/zero/1.0/) applies to the data made available in this article, unless otherwise stated in a credit line to the data. 


\section{Case presentation}

A 46-year-old male patient presented with a conjunctival infection and probable Reis-Bücklers dystrophy (clinically characterized by superficial corneal opacities, recurrent erosions and significant visual impairment), and multiple antimicrobial treatments showed no improvements. At admittance to our institution, the patient reported a headache and moderate pain in the bilateral orbitofrontal region radiating to the occipital region. $\mathrm{He}$ had a history of uncontrolled diabetes mellitus type 2 for 3 years and poor treatment compliance. A physical examination revealed fever, chills, and general malaise, with moderate bilateral ocular pain, nasal congestion, dehydrated nasal mucosa, odynophagia, cough, dyspnoea, hemoptysis, bilateral blepharoedema, and corneal opacity in the left eye (Fig. 1a, b). A black eschar was seen on the palate (Fig. 1c).

The patient was evaluated in the Ophthalmology Department, where a lacrimal gland biopsy was performed, and acute inflammation of the orbit of unknown origin was observed. A facial CT scan was performed and revealed pansinusitis with deformation of the left ocular globe, luxation of the crystalline, maxillary affectation, and deformation of the floor of the bilateral orbital bone occupied by both maxillary sinuses. The recommended starting treatment was liposomal amphotericin B $(5 \mathrm{mg} /$ $\mathrm{kg} /$ day) and the initiation of glycaemic control due to probable mucormycosis. A biopsy was taken, and

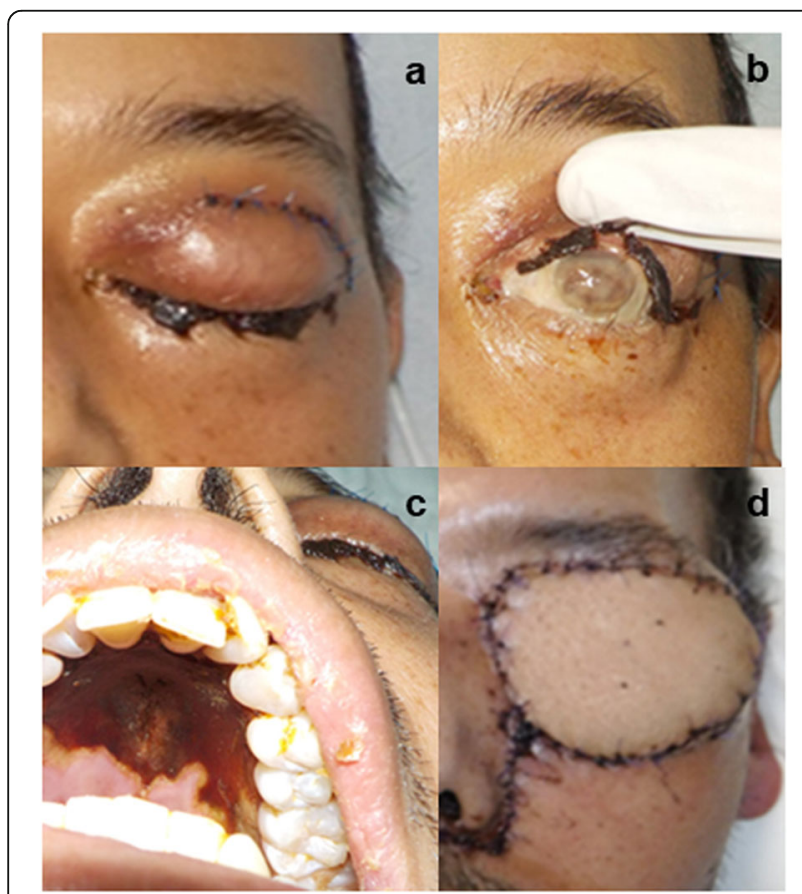

Fig. 1 Acute inflammation of the orbit of the left eye $\mathbf{a}$; corneal opacity of the left eye $\mathbf{b}$; oral cavity with necrotic ulcers $\mathbf{c}$; and total maxillectomy and exenteration of the left orbit $\mathbf{d}$ surgical debridement was performed with total maxillectomy and exenteration of the left orbit; a microvascularized femur graft was obtained to reconstruct the left orbit (Fig. 1d). During surgery, necrosis of the whole maxilla as well as the orbit floor, including the nasal septum, was observed. Samples of the maxillary tissue, ocular globe, and nasal septum were sent for histopathological analysis.

Haematoxylin-eosin and Grocott-Gomori staining allowed the observation of wide hyphae with irregular contours (Fig. 2), and a direct mycological study with $\mathrm{KOH} 10 \%$ revealed hyaline, coenocytic, long and wide filaments, compatible with members of the order Mucorales. No mycological culture was performed.

Molecular identification was performed by the amplification and sequencing of DNA fragments containing the $18 \mathrm{~S}$ rRNA gene, the internal transcribed spacer regions (ITS1, 5.8S gene, and ITS2), and the $5^{\prime}$ end of the $28 \mathrm{~S}$ rRNA gene. Genomic DNA was isolated from the maxillary tissue using a DNeasy blood and tissue kit (Qiagen, Ventura, CA, USA) according to the manufacturer's instructions. For polymerase chain reaction (PCR), a set of primers previously reported for fungal species (ITS1-5' TCCGTAGGTGAACCTGCGG-3' and ITS4-5' ${ }^{\prime}$-TCCT CCCGCTTATTGATATGC-3') was used $[8,9]$. The amplicon was purified, and the nucleotide sequence was determined in both directions with Taq FS dyeterminator cycle-sequencing fluorescence-based sequencing and analysed on an Applied Biosystems $3730 \mathrm{xl}$ DNA sequencing system. A PCR product of approximately $730 \mathrm{bp}$ was amplified from the maxillary sample. The PCR product was purified and sequenced in both

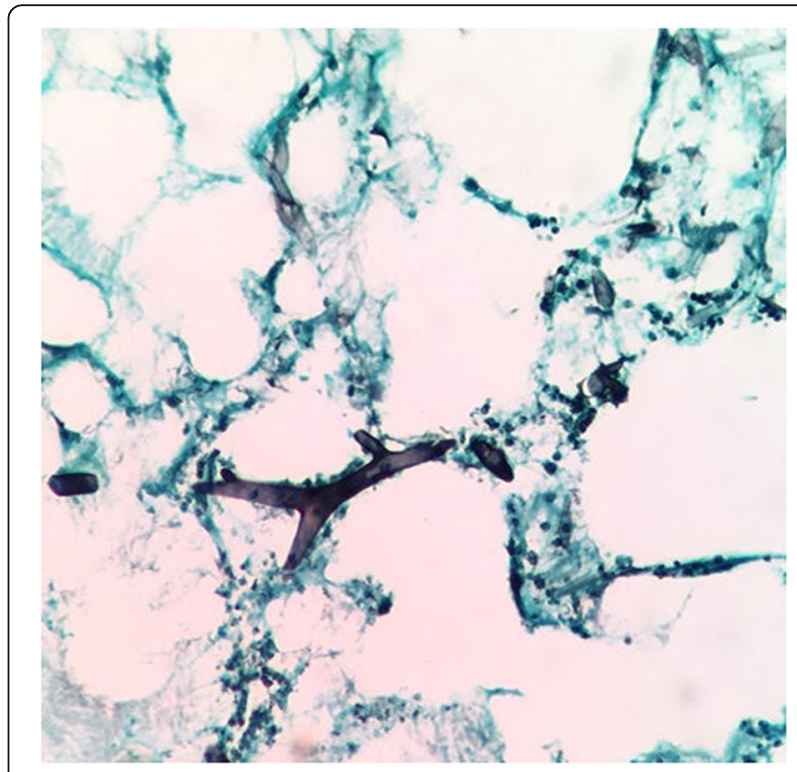

Fig. 2 Histopathological findings: wide and long non-septate hyphae with irregular contours (Grocott-Gomori staining, $\times 40$ ) 
directions using the same primers. A consensus sequence homology search was performed in the GenBank database (nucleotide BLAST); the obtained sequence showed 100\% homology with the Apophysomyces ossiformis UTHSC 04-838 strain, 99\% homology with the $A$. ossiformis UTHSC 07-204 strain, and 94\% homology with the $A$. thailandensis SDBR-CMUS219 and A. trapeziformis DUM101.13 strains.

Afterward, the patient was kept in the intensive care unit for 7 days and then transferred for continued hospitalization with an antibiotic regimen of piperacillintazobactam IV $4.5 \mathrm{~g} / 6 \mathrm{~h}$ and liposomal amphotericin B $(10 \mathrm{mg} / \mathrm{kg} /$ day $)$. On day 15 , the patient requested to return to the General Hospital of Tlaxcala to continue treatment. The patient died 9 days after admittance due to complications associated with his poorly controlled diabetes. Pneumonia caused by Klebsiella pneumoniae was present.

\section{Discussion and conclusion}

The global guideline for the diagnosis and management of mucormycosis was recently published by the European confederation of medical mycology. This initiative aims to generate actions that reduce mortality in patients through a rapid and specific diagnosis and therapeutic intervention, complemented with assistance of team surgery, radiology, and mycology laboratory [10].

Regarding the aetiology of mucormycosis, Rhizopus and Mucor spp. are found in $80 \%$ of cases; however, in recent years, Apophysomyces spp. have emerged as pathogens in both immunocompetent and immunocompromised individuals $[5,6,11]$. Although A. elegans was historically considered the only pathogenic species, other species (A. mexicanus, $A$. ossiformis, $A$. trapeziformis and $A$. variabilis) have been recently reported as infectioncausing agents [5-7]. The only case of infection by $A$. ossiformis was reported in an immunocompetent patient with humeral osteomyelitis [7]. In this work we report a rhino-orbital mucormycosis due to $A$. ossiformis in a patient with diabetes mellitus.

The incidence of infections due to Apophysomyces spp. has been frequently underestimated because the isolation and identification of Apophysomyces spp. is not easy, as it requires the use of culture media deficient in nutrients (Czapek-Dox agar), high incubation temperatures for growth $\left(37^{\circ} \mathrm{C}-42^{\circ} \mathrm{C}\right)$, and prolonged incubation times (7-10 days); additionally, their morphological characteristics often overlap with those of other species, hindering identification at the species level and thus leading to the need for molecular techniques $[11,12]$.

In our clinical case, the fungal isolation was unsuccessful because it was performed in Sabouraud dextrose agar, a culture medium that is not appropriate for the growth of Apophysomyces spp., as well as for the harsh processing of tissue. However, the visualization of hyphae characteristic of Mucorales allowed rapid action, such as surgical intervention in the affected area, the beginning of treatment and molecular identification.

From a clinical point of view, Apophysomyces can cause necrotizing fasciitis and renal and rhino-orbitalcerebral infections, and the treatment of choice is amphotericin B. However, research in a murine model showed the efficacy of posaconazole for the treatment of disseminated infections by $A$. variabilis. Further clinical studies are needed to determine the potential use of this antifungal agent in human infections $[11,13]$. Amphotericin $\mathrm{B}$ is the first-line antifungal monotherapy recommended by the global mucormycosis guide. There is no effective combination therapy so far; there are limited data about combinations of polyenes with azoles or polyenes with echinocandins [10].

Recently, the use of isavuconazole (a new antifungal drug) has been reported in cases of cutaneous and disseminated mucormycosis, rhino-orbital mucormycosis, and different Rhizopus species, as well as in $A$. elegans. The potent activity against these species shows that isavuconazole can be used as a primary or salvage treatment for mucormycosis [14-17].

The different Mucoral species are morphologically similar, which makes difficult the identification of species using mycological culture and morphological description. Because of this, the use of molecular techniques for identification is highly recommended and preferred. For molecular identification, the use of fresh material is better than formalin-fixed paraffin-embedded tissue because the formalin damages DNA. Among the most used molecular markers are the ITS, 18S, $28 \mathrm{~s}$ rRNA and cytochrome B. The global mucormycosis guide, the Clinical and Laboratory Standards Institute (CLSI) and the ISHAM Working Group on Fungal Molecular Identification coincide in recommending amplification and sequencing of the ITS region, as the most precise and accurate method for species identification [18-20].

Another alternative method for rapid identification is the MALDI-TOF mass spectrometry, especially when an in-house database is used and it is compared to commercial databases. MALDI-TOF is a promising technique that still requires validation, as well as a robust commercial database availability [21-23].

Notably, in this case, the aetiologic agent was identified as A. ossiformis, which constitutes, to the best of our knowledge, the first case rhino-orbital mucormycosis and the second case worldwide report of infection by this fungus. This case reveals the need to identify the fungus causing mucormycosis with molecular methods 
to identify adequate treatment therapies for patients, as it has been reported that $A$. variabilis is more susceptible to posaconazole than to amphotericin $\mathrm{B}$, the treatment of choice for mucormycosis. However, the responses of the other species in this genus to antifungal agents are currently unknown, and it is not known whether virulence differs among them.

\section{Abbreviations}

CT: Computed tomography; ITS: Internal transcribed spacer IV: intravenous; $\mathrm{KOH}$ : Potassium hydroxide

\section{Acknowledgements}

Not applicable.

\section{Authors' contributions}

EMH, MGFL, JXC, RHC: Conceived and designed study; AJC, LCB: Performed clinical interventions, EMH, MGFL, JXC, RHC: Analysed data. All authors read and approved the final manuscript.

\section{Funding}

Not applicable.

\section{Availability of data and materials}

The datasets generated and/or analysed during the current study are available from the corresponding author on reasonable request.

\section{Ethics approval and consent to participate}

This study was approved by the Institutional Review Board of the Regional Hospital of Ixtapaluca, Estado de México, México (NR-003-2018)

\section{Consent for publication}

Written informed consent was obtained from the patient's next of kin for publication of this case report and any accompanying images. A copy of the written consent for is available for review by the Editor-in-Chief of this journal.

\section{Competing interests}

The authors declare that they have no competing interests.

\section{Author details}

${ }^{1}$ Hospital Regional de Alta Especialidad de Ixtapaluca, Estado de México, Mexico. ${ }^{2}$ Laboratorio de Bacteriología Intestinal, Hospital Infantil de México "Dr. Federico Gómez", 06720 Ciudad de México, Cuauhtémoc, Mexico. ${ }^{3}$ Departamento de Ecología de Agentes Patógenos, Hospital General "Dr. Manuel Gea González", Sección XVI, Tlalpan 14080, Ciudad de México, Mexico.

Received: 13 December 2019 Accepted: 11 August 2020

Published online: 18 August 2020

\section{References}

1. Prabhu RM, Patel R. Mucormycosis and entomophthoramycosis: a review of the clinical manifestations, diagnosis and treatment. Clin Microbiol Infect. 2004;10:31-47.

2. Petrikkos G, Skiada A, Lortholary O, Roilides E, Walsh TJ, Kontoyiannis DP. Epidemiology and clinical manifestations of mucormycosis. Clin Infect Dis. 2012;54:23-34

3. Roden MM, Zaoutis TE, Buchanan WL, Knudsen TA, Sarkisova TA, Schaufele RL, Sein M, Sein T, Chiou CC, Chu JH, Kontoyiannis DP, Walsh TJ. Epidemiology and outcome of zygomycosis: a review of 929 reported cases. Clin Infect Dis. 2005:41:634-53.

4. Gomes MZR, Lewis RE, Kontoyiannis DP. Mucormycosis caused by unusual mucormycetes, non-Rhizopus, -Mucor, and -Lichtheimia species. Clin Microbiol Rev. 2011;24:411-45.

5. Alvarez E, Stchigel AM, Cano J, Sutton DA, Fothergill AW, Chander J, Salas V, Rinaldi MG, Guarro J. Molecular phylogenetic diversity of the emerging mucoralean fungus Apophysomyces: proposal of three new species. Rev Iberoam Micol. 2010;27:80-9.
6. Bonifaz A, Stchigel AM, Guarro J, Guevara E, Pintos L, Sanchis M. Primary cutaneous mucormycosis produced by the new species Apophysomyces mexicanus. J Clin Microbiol. 2014;52:4428-31.

7. Miller JT, Sheckter CC, Watt JA. Humeral osteomyelitis with Apophysomyces ossiformis in an immunocompetent patient: a case report. Surg Case Rep. 2019;2:1-3.

8. Arbefeville $\mathrm{S}$, Harris A, Ferrieri P. Comparison of sequencing the D2 region of the large subunit ribosomal RNA gene (MicroSEQ ${ }^{\oplus}$ ) versus the internal transcribed spacer (ITS) regions using two public databases for identification of common and uncommon clinically relevant fungal species. J Microbiol Methods. 2017:140:40-6.

9. Walther G, Pawłowska J, Alastruey-Izquierdo A, Wrzosek M, Rodriguez-Tudela JL, Dolatabadi S, Chakrabarti A, de Hoog GS. DNA barcoding in Mucorales: an inventory of biodiversity. Persoonia. 2013;30:11-47.

10. Cornely OA, Alastruey-Izquierdo A, Arenz D, Chen SCA, Dannaoui E, Hochhegger B, et al. Global guideline for the diagnosis and management of mucormycosis: an initiative of the European Confederation of Medical Mycology in cooperation with the Mycoses Study Group Education and Research Consortium. Lancet Infect Dis. 2019;19:e405-21.

11. Guarro J, Chander J, Alvarez E, Stchigel AM, Robin K, Dalal U, Rani H, Punia RS, Cano JF. Apophysomyces variabilis infections in humans. Emerg Infect Dis. 2011:17:134-5.

12. Padhye AA, Ajello L. Simple method of inducing sporulation by Apophysomyces elegans and Saksenaea vasiformis. J Clin Microbiol. 1988;26: 1861-3.

13. Salas V, Pastor FJ, Calvo E, Sutton DA, Chander J, Mayayo E, Alvarez E, Guarro J. Efficacy of posaconazole in a murine model of disseminated infection caused by Apophysomyces variabilis. J Antimicrob Chemother. 2012;67:1712-5

14. Chakrabarti A, Shivaprakash MR, Curfs-Breuker I, Baghela A, Klaassen CH, Meis JF. Apophysomyces elegans: epidemiology, amplified fragment length polymorphism typing, and in vitro antifungal susceptibility pattern. J Clin Microbiol. 2010:48:4580-5.

15. Peixoto D, Gagne LS, Hammond SP, Gilmore ET, Joyce AC, Soiffer RJ, Marty FM. Isavuconazole treatment of a patient with disseminated mucormycosis. J Clin Microbiol. 2014;52:1016-9.

16. Itharco M, Pereira CM, Moreira L, Proença AL, do Carmo Fevereiro M, Lampreia F, Oliveira ML, Rola J. Rhinoorbital mucormycosis in the immunocompetent: experience with isavuconazole. ID Cases. 2019;9(18): e00591.

17. Zuglian G, Ripamonti D, Tebaldi A, Rizzi M. Cutaneous mucormycosis by Rhizopus arrhizus treated with isavuconazole as first line therapy: A case report. Med Mycol Case Rep. 2019;26:42-3.

18. Clinical and laboratory Standards Institute (CLSI). Interpretive criteria for bacteria and fungi identification by DNA target sequencing; Approved Guideline MM-18A: Clinical and Laboratory Standards Institute, Wayne, Pa, 2008

19. Balajee SA, Borman AM, Brandt ME, Cano J, Cuenca-Estrella M, Dannaoui E, et al. Sequence-based identification of Aspergillus, Fusarium, and mucorales species in the clinical mycology laboratory: where are we and where should we go from here? J Clin Microbiol. 2009;47:877-84.

20. Baldin C, Soliman SSM, Jeon HH, Alkhazraji S, Gebremariam T, Gu Y, et al. PCR-based approach targeting mucorales-specific gene family for diagnosis of mucormycosis. J Clin Microbiol. 2018;56:1-12.

21. Becker PT, de Bel A, Martiny D, Ranque S, Piarroux R, Cassagne C, et al. Identification of filamentous fungi isolates by MALDI-TOF mass spectrometry: clinical evaluation of an extended reference spectra library. Med Mycol. 2014;52:826-34.

22. McMullen AR, Wallace MA, Pincus DH, Wilkey K, Burnham CA. Evaluation of the Vitek MS matrix-assisted laser desorption ionization-time of flight mass spectrometry system for identification of clinically relevant filamentous fungi. J Clin Microbiol. 2016;54:2068-73.

23. Shao J, Wan Z, Li R, Yu J. Species identification and delineation of pathogenic mucorales by matrix-assisted laser desorption ionization-time of flight mass spectrometry. J Clin Microbiol. 2018;56:1-8.

\section{Publisher's Note}

Springer Nature remains neutral with regard to jurisdictional claims in published maps and institutional affiliations. 